\title{
Alteration of Taste Acuity in Pediatric Cancer Patients after Treatment Completion: A Cross-Sectional Study Using a Filter-Paper Disc Method
}

\author{
Ayako Nagai', Masaru Kubota1*, Souichi Adachi2, Ken-ichiro Watanabe², \\ Yasufumi Takeshita ${ }^{3}$ \\ ${ }^{1}$ Department of Human Life and Environment, Nara Women's University, Nara, Japan \\ ${ }^{2}$ Department of Pediatrics, Kyoto University Hospital, Kyoto, Japan \\ ${ }^{3}$ Department of Pediatrics, Nara Medical University Hospital, Nara, Japan \\ Email: masaru kubota@chim.ocn.ne.jp
}

Received 14 June 2014; revised 18 July 2014; accepted 28 July 2014

Copyright (C) 2014 by authors and Scientific Research Publishing Inc.

This work is licensed under the Creative Commons Attribution International License (CC BY). http://creativecommons.org/licenses/by/4.0/

(c) (i) Open Access

\begin{abstract}
Taste acuity of adult patients undergoing cancer treatment has been well investigated; however, studies of taste acuity after completion of cancer treatment are limited, particularly in children. This study aimed to assess taste acuity in pediatric cancer patients after treatment completion. Seventy-three patients who had completed cancer treatment (median age, 13 years; range, 7 - 18 years) and had not received any further treatment for at least 6 months were enrolled. Eighty-one healthy children (median age, 10 years; range, 8 - 19 years) served as controls. We determined the thresholds for four tastes (sweet, salty, sour, and bitter) using the filter-paper disc method. There was no significant difference in the thresholds of taste acuity for the four test solutions between the patient and control groups. The duration since treatment completion $(<5$ years vs. $\geq 5$ years) had no significant impact on taste acuity for the four test solutions. The threshold for tasting salt was significantly higher in the group that had received chemotherapy + radiation and/or hematopoietic stem cell transplantation than that in the group that had received chemotherapy-only. Our results indicated that taste acuity after treatment completion in pediatric cancer patients was the same as that in healthy children. However, some treatment modalities were correlated with an impaired ability to taste salt. Gustatory test results should be considered while deciding nutritional support modalities after treatment completion in pediatric cancer patients.
\end{abstract}

\section{Keywords}

Pediatric Cancer, Cancer Treatment, Filter-Paper Disc Method, Taste Acuity

\footnotetext{
${ }^{*}$ Corresponding author.
} 


\section{Introduction}

Taste acuity plays an important role in nutritional preference. In studies involving healthy populations, older age and male gender were identified as predictive factors for impaired taste acuity [1] [2]. Furthermore, changes in taste acuity have been reported in adult patients with various disorders, including chronic renal failure treated by peritoneal dialysis [3], Parkinson's disease [4], rheumatoid arthritis [5], and chronic hepatitis C [6]. Changes in taste acuity are also common in adult cancer patients, presumably because of malnutrition and emotional stress caused by cancer and/or cancer treatment [7]. Taste acuity of cancer patients, particularly during the period of chemotherapy or radiotherapy, has been extensively studied [8] [9]. The prevalence of taste alterations among adult patients undergoing cancer treatment reportedly ranges from $46 \%$ to $77 \%$, depending on cancer type, treatment modality, and method of taste acuity evaluation [10]-[13]. Although the mechanisms underlying taste alterations in these patients have not been fully identified, several possibilities have been proposed, including direct injury to taste buds, damage to the nervous system after surgery or local anesthesia, alterations in saliva excretion, and zinc deficiency [14] [15].

In general, impairment of taste acuity reportedly occurs more frequently in adult patients with solid malignancies such as breast and ovarian tumors than that in those with hematological malignancies [16]-[18]. In these reports, platinum-containing drugs [17] or taxanes [18] were thought to be responsible for taste alterations. Radiation therapy [19] [20] and hematopoietic stem cell transplantation (HSCT) [21] are also factors influencing taste alterations. Most studies on taste acuity involve adult cancer patients, with relatively few studies evaluating taste acuity in pediatric cancer patients [22]-[24]. However, these studies included a limited number of patients undergoing chemotherapy or HSCT, and none evaluated changes in taste acuity in pediatric cancer patients after treatment completion. Considering that the prognosis of childhood cancer has improved in recent decades [25], it is important to evaluate changes in taste acuity in pediatric cancer survivors to ensure that they consume an adequate diet.

\section{Methods}

\subsection{Study Subjects}

This cross-sectional study was conducted at two hospitals, Kyoto University Hospital and Nara Medical University Hospital. Seventy-three children (median age, 13 years; range, 7 - 18 years) who completed treatment for pediatric cancer were enrolled in this study. The cancer types included acute lymphoblastic leukemia, acute myeloid leukemia, lymphoma, Langerhans cell histiocytosis, brain cancer, and other solid cancers. Patients who met the following criteria were enrolled: age $>6$ years at the time of study enrollment and no cancer treatment for at least 6 months prior to enrollment. We selected patients aged $>6$ years because previous investigators established that children could recognize four basic tastes at the age of 6 years using the gustatory test [26] [27]. Eighty-one healthy children (median age, 10 years; range, 8 - 19 years) served as a control group. These children were students of an elementary school attached to Nara Women's University, Nara Women's University secondary school, Nara Women's University, and Kyoto Bunkyo University. Their age and gender distributions were not statistically different from those in the patients group. The characteristics of the patients and controls are shown in Table 1. Patients had a regular diet throughout the study period without restricting any specific foods. The study protocol was approved by the ethical and epidemiological committees of Nara Women's University and the two hospitals participating in this study. Patients themselves provided written informed consent if they were older than 15 years, while a parent or guardian provided consent for patients younger than 15 years.

\subsection{Taste Acuity Measurement}

The gustatory test was conducted in the morning at a fasting state by a trained dietitian (author AN) using the filter-paper disc (FPD) method [28]. The children's recognition thresholds for four basic tastes were evaluated using test solutions (sweet, sucrose; salty, sodium chloride; sour, tartaric acid; and bitter, quinine hydrochloride) [28] (Taste disc ${ }^{\circledR}$; Sanwa Chemical Co., Ltd., Nagoya, Japan). The test solutions included five grades of concentrations, with grade 1 being the lowest concentration and grade 5 being the highest. The exact concentrations used for the four test solutions were 8.8, 74, 292, 584, and $2336 \mathrm{mM}$ for sucrose (sweet); 51.4, 214, 856, 1714, and $3420 \mathrm{mM}$ for sodium chloride (salty); 1.3, 13.3, 133, 266, and $532 \mathrm{mM}$ for tartaric acid (sour); and 0.025, 0.5, 2.5, 12.5, and $100 \mathrm{mM}$ for quinine hydrochloride (bitter) [29]. 
Table 1. Characteristics of the patients and the controls.

\begin{tabular}{|c|c|c|c|}
\hline & Patients & Controls & \\
\hline & $(n=73)$ & $(n=81)$ & $p$ \\
\hline \multicolumn{4}{|l|}{ Gender $^{* *}$} \\
\hline Male & $42(57.5)$ & 39 (48.1) & \multirow{2}{*}{$0.24^{\#}$} \\
\hline Female & $31(42.5)$ & $42(51.9)$ & \\
\hline Present age (year) ${ }^{* * *}$ & $13(7-18)$ & $10(8-19)$ & $0.13^{\# \#}$ \\
\hline Age at diagnosis (year) ${ }^{* * *}$ & $4.5(0.5-14)$ & - & - \\
\hline Duration after completion of treatment (year) ${ }^{* * *}$ & $6.5(0.5-13)$ & - & - \\
\hline \multicolumn{4}{|l|}{ Treatment $^{* *}$} \\
\hline Chemotherapy only & $40(54.8)$ & - & - \\
\hline Chemotherapy + radiation $\dagger$ & $8(11.0)$ & - & - \\
\hline Chemotherapy + HSCT & $5(6.8)$ & - & - \\
\hline Chemotherapy + radiation $\neq+$ HSCT & $20(27.4)$ & - & - \\
\hline \multicolumn{4}{|l|}{ Diagnosis $^{* *}$} \\
\hline Acute lymphoblastic leukemia & $46(63.0)$ & - & - \\
\hline Acute myeloid leukemia & $4(5.5)$ & - & - \\
\hline Lymphoma $^{\mathrm{a}}$ & $8(11.0)$ & - & - \\
\hline Langerhans cell histiocytosis & $3(4.1)$ & - & - \\
\hline Brain tumor & $5(6.8)$ & - & - \\
\hline Others $^{\mathrm{b}}$ & $7(9.6)$ & - & - \\
\hline Recurrence $^{* *}$ & $14(19.2)$ & - & - \\
\hline
\end{tabular}

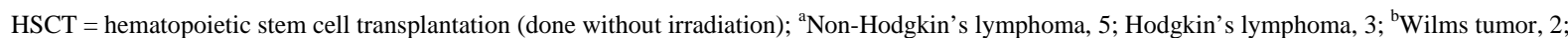
Retinoblastoma, 2; Neuroblastoma, 1; Hepatoblastoma, 1; Teratoma, 1 ; ${ }^{\#}$ Chi-square test; ${ }^{* \#}$ Mann-Whitney U-test; ${ }^{* *}$ Number (percentage); ${ }^{* * *}$ Median (range); ${ }^{\dagger}$ Only cranial irradiation; †Cranial and/or total body irradiation.

During the test, each child's mouth was rinsed with distilled water before testing the next concentration. After rinsing, a 5-mm test disc saturated with the test solution was placed on the left lateral part of the tongue, approximately $2 \mathrm{~cm}$ from the proglossis (i.e., the locus of the chorda tympani nerve), for a few seconds. The test was initiated with the lowest concentration, which was gradually increased until the taste was recognizable. An interval of at least 1 min was allowed between testing each concentration. The concentrations at each taste were serially scored from disc number 1 (lowest) to number 5 (highest). The lowest concentration at which the specific taste was correctly identified was defined as the recognition threshold. If the child could not detect the taste at the highest concentration, a score of 6 was assigned [30].

\subsection{Statistical Analysis}

Differences in demographic characteristics and taste acuity between the patients and controls were analyzed using the Chi-squared test and the Mann-Whitney U-test. The Chi-squared test was used to evaluate differences in the recognition of taste at each concentration between the patients and controls. The Chi-squared test was also used to analyze differences in taste acuity between groups stratified by duration since treatment completion and treatment modality. All statistical analyses were performed using Excel Statistics software (ver. 2010; SSRI Co., Ltd., Tokyo, Japan). A $p$-value of $<0.05$ was considered statistically significant.

\section{Results}

\subsection{Comparison of Taste Acuity between Patients and Controls}

The proportion of study participants in the patient and control groups who were able to taste the four test solutions at each concentration is shown in Figure 1(a) and Figure 1(b), respectively. There was no significant difference in the distribution of taste recognition at each concentration of the four test solutions between the patient and control groups.

\subsection{Effect of Duration since Treatment Completion on Taste Acuity}

To determine whether duration since treatment completion had an effect on taste acuity, we divided the patients into a group that had completed treatment $<5$ years back and a group that had completed treatment $>5$ years back. 
(a) Patients

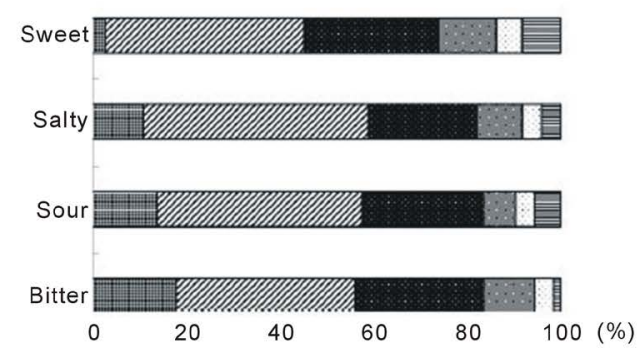

(b) Controls

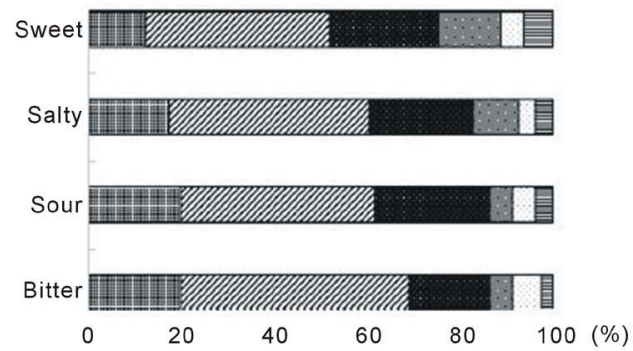

Figure 1. Distribution of taste acuity for each concentration of the four test solutions (sweet, salty, sour, and bitter). (a)

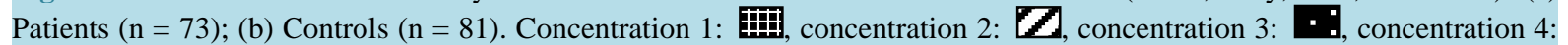
, concentration 5: $\therefore$, and concentration 6: Differences between the two groups as determined by the Chi-squared test were as follows: sweet, $p=0.38$; salty, $p=0.93$; sour, $p=0.92$; and bitter, $p=0.39$.

As shown in Figure 2, there were no significant differences in the distribution of recognition thresholds for the four test solutions between the two groups.

\subsection{Comparison of Taste Acuity between Chemotherapy-0nly and Chemotherapy + Radiation and/or HSCT Groups}

The patients were divided into two groups on the basis of treatment received: chemotherapy-only and chemotherapy + radiation and/or HSCT. As shown in Figure 3, the chemotherapy-only group had a significantly higher threshold for tasting the salty solution compared with the chemotherapy + radiation and/or HSCT group. However, there was no significant difference between groups in the threshold for tasting the other three test solutions.

\section{Discussion}

Taste alteration, which may cause a loss of appetite that leads to malnutrition and/or weight loss, is a serious problem experienced by many cancer patients [8] [9]. Among several treatment modalities, chemotherapeutic agents, radiation, and HSCT are regarded as major causes of taste alterations [8] [9]. Bernhardson et al. [11] reported that $67 \%$ patients with various types of cancer (breast, gastrointestinal, and gynecological) experienced taste alterations during chemotherapy. Zabernigg et al. [31] demonstrated that the incidence of taste alterations was the highest for patients with pancreatic, lung, or colorectal cancer treated by irinotecan followed by a combination of 5-fluorouracil and oxaliplatin. Taxanes and other platinum-containing agents have also been reported to cause impaired taste acuity in adult patients with breast or gynecological cancer [16] [17]. However, no specific regimens or chemotherapeutic agents have been reported to cause taste alterations in pediatric cancer patients.

Another factor that needs investigation is the duration for which these taste alterations last in cancer patients. Steinbach et al. [16] examined gustatory function in 87 adult cancer patients using the FPD method before, during, directly after, and 3 months after the completion of chemotherapy. They found that taste acuity for the four tastes decreased uniformly during and directly after chemotherapy and returned to pretreatment levels 3 months after chemotherapy completion. Yamashita et al. [32] reported that the taste dysfunction experienced by headand-neck cancer patients who had received radiation to the anterior part of the tongue was temporary. Ruo Redda and Allis [33] described patients in whom taste alterations lasted for $>6$ months after irradiation. Marinone et al. [34] reported that the thresholds for salty and sour tastes significantly increased in 15 adult patients at 4 - 51 months after HSCT compared with those in 20 healthy subjects. Boer et al. [35] reported that impairments in recognizing sweet and salty tastes persisted for up to 3 years after HSCT. Barale et al. [22] assessed the recognition thresholds for the four tastes in 11 children who had undergone HSCT and found that the threshold for salty taste significantly increased 2 days after transplantation and returned to the pretreatment level 45 days after transplantation.

In the present study, the gustatory test was conducted for pediatric cancer patients with at least a 6-month duration since treatment completion. We found that taste acuity of these patients was, as a cohort, almost equal tothat of healthy controls. With regard to the duration since treatment completion, we failed to detect any sig- 

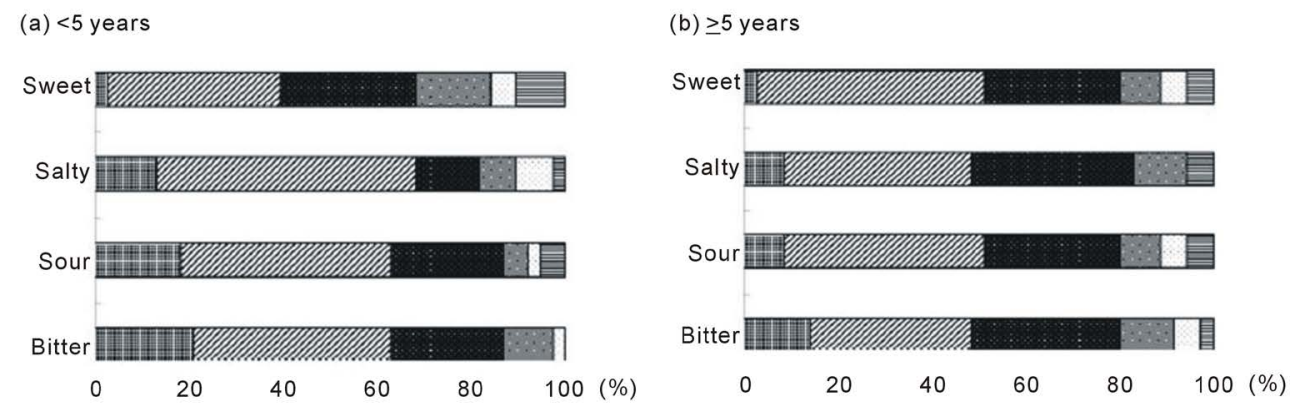

Figure 2. Distribution of taste acuity for each concentration of the four test solutions (sweet, salty, sour, and bitter) in patients stratified by duration since treatment completion. (a) $<5$ years $(\mathrm{n}=38)$; (b) $\geq 5$ years $(\mathrm{n}=35)$. Concentration 1 : 曲, concentration 2: $\mathscr{Z}$, concentration 3: $\because$, concentration 4: $\cong$, concentration 5: $\therefore$, and concentration 6 : Differences between the two groups as determined by the Chi-squared test were as follows: sweet, $p=0.86$; salty, $p=0.15$; sour, $p=0.82$; and bitter, $p=0.75$.
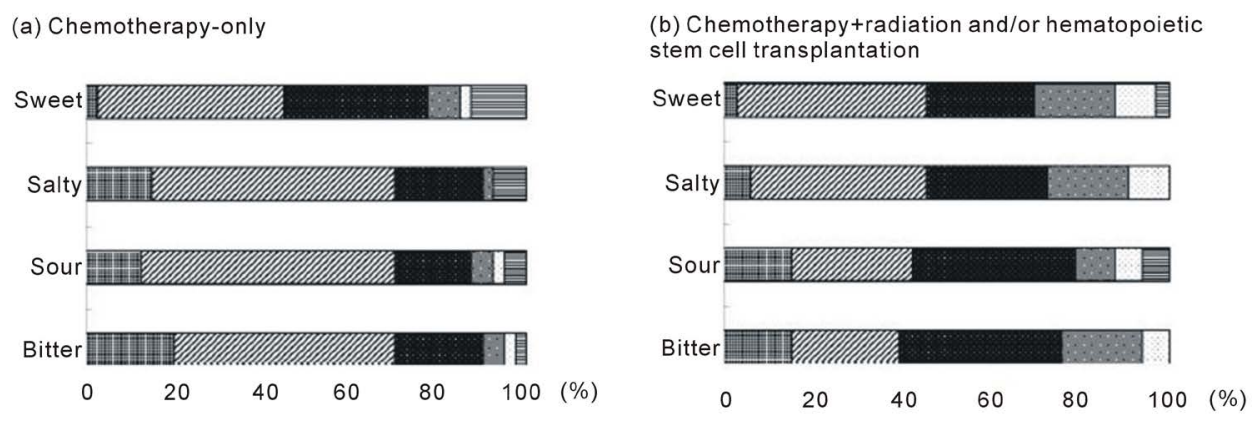

Figure 3. Distribution of taste acuity for each concentration of the four test solutions (sweet, salty, sour, and bitter) in patients stratified by treatment received. (a) Chemotherapy-only $(\mathrm{n}=40)$; (b) Chemotherapy + radiation and/or hematopoietic

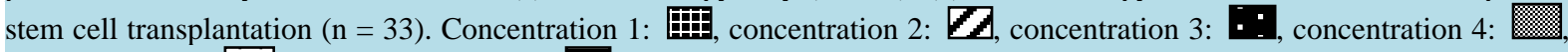
concentration 5: $\therefore$, and concentration 6: Differences between the two groups as determined by the Chi-squared test were as follows: sweet, $p=0.36$; salty, $p=0.02$; sour, $p=0.19$; and bitter, $p=0.09$.

nificant effect when we used a 5-year cut-off duration. We selected this cut-off duration in the present study because a previous study determined that taste alterations did not generally last for $>5$ years after HSCT [34]. When other cut-off durations were used for statistical analysis (i.e., 3 and 10 years), the results were almost identical to those obtained when a 5-year cut-off was used. This may be because only those patients with at least a 6-month duration since treatment completion were included. However, to determine a baseline level for taste acuity, patients should be tested before or immediately after treatment completion.

In addition, in the present study, patients who had received chemotherapy + radiation and/or HSCT had decreased taste acuity for salt compared with patients who had received chemotherapy only. This result is consistent with those of previous studies conducted by Ruo Redda et al. [33], Marinone et al. [34], and Boer et al. [35], although taste impairments differed among the three studies; the impairments were for salty and bitter tastes in one study [33], salty and sour tastes in another [34], and sweet and salty tastes in the third [35]. The reason for these discrepancies remains uncertain at present.

The present study had several limitations. First, the types of cancer were quite heterogeneous, making it difficult to draw definitive conclusions. Second, this was a cross-sectional study; therefore, taste acuity of each patient was measured only once. For a better understanding of changes in taste acuity after cancer treatment completion, serial measurements of taste acuity are required, including measurement immediately after treatment completion. This study also had its strengths. First, as per our knowledge, this was the first study to evaluate taste acuity after treatment completion in pediatric cancer patients using the FPD method. Second, an age- and gender-matched control group, which was lacking in most previous studies, was included.

The findings of this study demonstrated no significant differences in acuity for four basic tastes between pediatric cancer patients who had undergone treatment and healthy controls, indicating that the persistence of taste 
alterations, if any, may be marginal after a certain period has lapsed since treatment completion in pediatric cancer patients. However, the results also indicated that the acuity for specific tastes may differ with treatment modality. Since taste acuity is thought to influence nutritional preference, careful observation of nutritional status in pediatric cancer survivors, including evaluation of their at-home diets, is necessary. Further studies are needed to investigate changes in taste acuity in pediatric cancer patients during and immediately after treatment.

\section{Acknowledgements}

This work was supported by a Grant-in-Aid for Scientific Research (grant no. 23700903). We wish to thank Dr. $\mathrm{H}$. Tomita for his pertinent advice on gustatory testing using the FPD method.The authors would like to thank Enago (www.enago.jp) for the English language review.

\section{Competing Interests}

The authors declare that they have no competing interests.

\section{References}

[1] Wardwell, L., Chapman-Novakofski, K. and Brewer, M.S. (2009) Effect of Age, Gender, and Chronic Obstructive Disease on Taste Acuity. International Journal of Food Science and Nutrition, 60, 84-97. http://dx.doi.org/10.1080/09637480802710224

[2] Simpson, E.E., Rae, G., Parr, H., O’Connor, J.M., Bonham, M., et al. (2012) Predictors of Taste Acuity in Healthy Older Europeans. Appetite, 58, 188-195. http://dx.doi.org/10.1016/j.appet.2011.09.007

[3] Middleton, R.A. and Allman-Farinelli, M.A. (1999) Taste Sensitivity Is Altered in Patients with Chronic Renal Failure Receiving Continuous Ambulatory Peritoneal Dialysis. Journal of Nutrition, 129, 122-125.

[4] Kashihara, K., Hanaoka, A. and Imamura, T. (2011) Frequency and Characteristics of Taste Impairment in Patients with Parkinson's Disease: Results of a Clinical Review. Internal Medicine, 50, 2311-2315. http://dx.doi.org/10.2169/internalmedicine.50.5935

[5] Steinbach, S., Proft, F., Schulze-Koops, H., Hundt, W., Heinrich, P., et al.(2011) Gustatory and Olfactory Function in Rheumatoid Arthritis. Scandinavian Journal of Rheumatology, 40, 169-177. http://dx.doi.org/10.3109/03009742.2010.517547

[6] Musialik, J., Suchecka, W., Klimacka-Nawrot, E., Petelenz, M., Hartman, M., et al. (2012) Taste and Appetite Disorders of Chronic Hepatitis C Patients. European Journal of Gastroenterology and Hepatology, 24, 1400-1405. http://dx.doi.org/10.1097/MEG.0b013e3283589f63

[7] Ravasco, P. (2005) Aspects of Taste and Compliance in Patients with Cancer. European Journal of Oncology Nursing, 9, S84-S91. http://dx.doi.org/10.1016/j.ejon.2005.09.003

[8] Gamper, E.M., Zabernigg, A., Wintner, L.M., Giesinger, J.M., Oberguggenberger, A., et al. (2012) Coming to Your Senses: Detecting Taste and Smell Alterations in Chemotherapy Patients. A Systematic Review. Journal of Pain Symptom Management, 44, 880-895. http://dx.doi.org/10.1016/j.jpainsymman.2011.11.011

[9] Hong, J.H., Omur-Ozbek, P., Stanek, B.T., Dietrich, A.M., Duncan, S.E., et al. (2009) Taste and Odor Abnormalities in Cancer Patients. The Journal of Supportive Oncology, 7, 758-765.

[10] Wickham, R.S., Rehwaldt, M., Kefer, C., Shott, S., Abbas, K., et al. (1999) Taste Changes Experienced by Patients Receiving Chemotherapy. Oncology Nursing Forum, 26, 697-706.

[11] Bernhardson, B.M., Tishelman, C. and Rutqvist, L.E. (2008) Self-Reported Taste and Smell Changes during Cancer Chemotherapy. Supportive Care in Cancer, 16, 275-283. http://dx.doi.org/10.1007/s00520-007-0319-7

[12] Lindley, C., McCune, J.S., Thomason, T.E., Lauder, D., Sauls, A., Adkins, S. and Sawyer, W.T. (1999) Perception of Chemotherapy Side Effects Cancer versus Noncancer Patients. Cancer Practice, 7, 59-65. http://dx.doi.org/10.1046/j.1523-5394.1999.07205.x

[13] Epstein, J.B., Emerton, S., Kolbinson, D.A., Le, N.D., Phillips, N., Stevenson-Moore, P. and Osoba, D. (1999) Quality of Life and Oral Function Following Radiotherapy for Head and Neck Cancer. Head \& Neck, 21, 1-11. http://dx.doi.org/10.1002/(SICI)1097-0347(199901)21:1<1::AID-HED1>3.0.CO;2-4

[14] Schiffman, S.S. (1983) Taste and Smell in Disease (Second of Two Parts). New England Journal of Medicine, 308, 1337-1343. http://dx.doi.org/10.1056/NEJM198306023082207

[15] Epstein, J.B., Thariat, J., Bensadoun, R.J., Barasch, A., Murphy, B.A., Kolnick, L., Popplewell, L. and Maghami, E. (2012) Oral Complications of Cancer and Cancer Therapy from Cancer Treatment to Survivorship. CA: A Cancer Journal for Clinicians, 62, 400-422. http://dx.doi.org/10.3322/caac.21157

[16] Steinbach, S., Hummel, T., Böhner, C., Berktold, S., Hundt, W., et al. (2009) Qualitative and Quantitative Assessment 
of Taste and Smell Changes in Patients Undergoing Chemotherapy for Breast Cancer or Gynecologic Malignancies. Journal of Clinical Oncology, 27, 1899-1905. http://dx.doi.org/10.1200/JCO.2008.19.2690

[17] Steinbach, S., Hundt, W., Schmalfeldt, B., Böhner, C., Berktold, S., Wolf, P. and Harbeck, N. (2012) Effect of Platinum-Containing Chemotherapy on Olfactory, Gustatory, and Hearing Function in Ovarian Cancer Patients. Archives of Gynecology and Obstetrics, 286, 473-480. http://dx.doi.org/10.1007/s00404-012-2307-5

[18] Speck, R.M., DeMichele, A., Farrar, J.T., Hennessy, S., Mao, J.J., Stineman, M.G. and Barg, F.K. (2013) Taste Alteration in Breast Cancer Patients Treated with Taxane Chemotherapy: Experience, Effect, and Coping Strategies. Supportive Care in Cancer, 21, 549-555. http://dx.doi.org/10.1007/s00520-012-1551-3

[19] Sandow, P.L., Hejrat-Yazdi, M. and Heft, M.W. (2006) Taste Loss and Recovery Following Radiation Therapy. Journal of Dental Research, 85, 608-611. http://dx.doi.org/10.1177/154405910608500705

[20] Oates, J.E., Clark, J.R., Read, J., Reeves, N., Gao, K., Jackson, M., Boyer, M. and O’brien, C.J. (2007) Prospective Evaluation of Quality of Life and Nutrition before and after Treatment for Nasopharyngeal Carcinoma. Archives of Otolaryngology — Head and Neck Surgery, 133, 533-540.

[21] Epstein, J.B., Phillips, N., Parry, J., Epstein, M.S., Nevill, T. and Stevenson-Moore, P. (2002) Quality of Life, Taste, Olfactory and Oral Function Following High-Dose Chemotherapy and Allogeneic Hematopoietic Cell Transplantation. Bone Marrow Transplantation, 30, 785-792. http://dx.doi.org/10.1038/sj.bmt.1703716

[22] Barale, K., Aker, S.N. and Martinsen, C.S. (1982) Primary Taste Thresholds in Children with Leukemia Undergoing Marrow Transplantation. Journal of Parenteral and Enteral Nutrition, 6, 287-290. http://dx.doi.org/10.1177/0148607182006004287

[23] Skolin, I., Wahlin, Y.B., Broman, D.A., Koivisto Hursti, U.K., Vikström Larsson, M. and Hernell, O. (2006) Altered Food Intake and Taste Perception in Children with Cancer after Start of Chemotherapy: Perspectives of Children, Parents and Nurses. Supportive Care in Cancer, 14, 369-378. http://dx.doi.org/10.1007/s00520-005-0904-6

[24] Cohen, J., Laing, D.G. and Wikes, F.J. (2012) Taste and Smell Function in Pediatric Blood and Marrow Transplant Patients. Supportive Care in Cancer, 20, 3019-3023. http://dx.doi.org/10.1007/s00520-012-1559-8

[25] Stiller, C.A., Kroll, M.E. and Pritchard-Jones, K. (2012) Population Survival from Childhood Cancer in Britain during 1978-2005 by Eras of Entry to Clinical Trials. Annals of Oncology, 23, 2464-2469. http://dx.doi.org/10.1093/annonc/mds183

[26] Majorana, A., Campus, G., Anedda, S., Piana, G., Bossù, M., et al. (2012) Italian Study Group on Taste Disorders. Development and Validation of a Taste Sensitivity Test in a Group of Healthy Children. European Journal of Paediatric Dentistry, 13, 147-150.

[27] Overberg, J., Hummel, T., Krude, H. and Wiegand, S. (2012) Differences in Taste Sensitivity between Obese and Non-Obese Children and Adolescents. Archives of Disease in Childhood, 97, 1048-1052. http://dx.doi.org/10.1136/archdischild-2011-301189

[28] Tsuruoka, S., Wakaumi, M., Nishiki, K., Araki, N., Harada, K., Sugimoto, K. and Fujimura, A. (2004) Subclinical Alteration of Taste Sensitivity Induced by Candesartan in Healthy Subjects. British Journal of Clinical Pharmacology, 57, 807-812. http://dx.doi.org/10.1111/j.1365-2125.2003.02063.X

[29] Nagai, A., Kubota, M., Katayama, Y. and Kojima, C. (2012) Evaluation of Taste Acuity by the Filter-Paper Disc in Japanese Young Women: The Relationship with Micronutrients Status. Asia Pacific Journal of Clinical Nutrition, 21, 406-410.

[30] Nishijima, S., Yanase, T., Tsuneki, I., Tamura, M. and Kurabayashi, T. (2013) Examination of the Taste Disorder Associated with Gynecological Cancer Chemotherapy. Gynecologic Oncology, 131, 674-678. http://dx.doi.org/10.1016/j.ygyno.2013.09.015

[31] Zabernigg, A., Gamper, E.M., Giesinger, J.M., Rumpold, G., Kemmler, G., Gattringer, K., Sperner-Unterweger, B. and Holzner, B. (2010) Taste Alterations in Cancer Patients Receiving Chemotherapy: A Neglected Side Effect? The Oncologist, 15, 913-920. http://dx.doi.org/10.1634/theoncologist.2009-0333

[32] Yamashita, K., Nakagawa, K., Nakamura, N., Abe, K., Asakage, T., et al. (2006) Relation between Acute and Late Irradiation Impairment of Four Basic Tastes and Irradiated Tongue Volume in Patients with Head-and-Neck Cancer. International Journal of Radiation Oncology Biology Physiology, 66, 1422-1429. http://dx.doi.org/10.1016/j.ijrobp.2006.08.037

[33] Ruo Redda, M.G. and Allis, S. (2006) Radiotherapy-Induced Taste Impairment. Cancer Treatment Reviews, 32, 541547. http://dx.doi.org/10.1016/j.ctrv.2006.06.003

[34] Marinone, M.G., Rizzoni, D., Ferremi, P., Rossi, G., Izzi, T. and Brusotti, C. (1991) Late Taste Disorders in Bone Marrow Transplantation: Clinical Evaluation with Taste Solutions in Autologous and Allogeneic Bone Marrow Recipients. Haematologica, 76, 519-522.

[35] Boer, C.C., Correa, M.E.P., Miranda, E.C.M. and De Souza, C.A. (2010) Taste Disorders and Oral Evaluation in Patients Undergoing Allogeneic Hematopoietic SCT. Bone Marrow Transplantation, 45, 705-711. http://dx.doi.org/10.1038/bmt.2009.237 
Scientific Research Publishing (SCIRP) is one of the largest Open Access journal publishers. It is currently publishing more than 200 open access, online, peer-reviewed journals covering a wide range of academic disciplines. SCIRP serves the worldwide academic communities and contributes to the progress and application of science with its publication.

Other selected journals from SCIRP are listed as below. Submit your manuscript to us via either submit@scirp.org or Online Submission Portal.
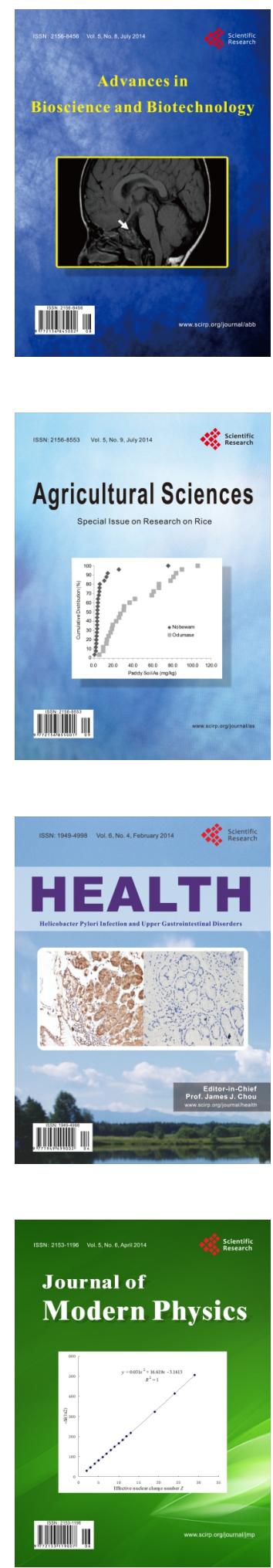
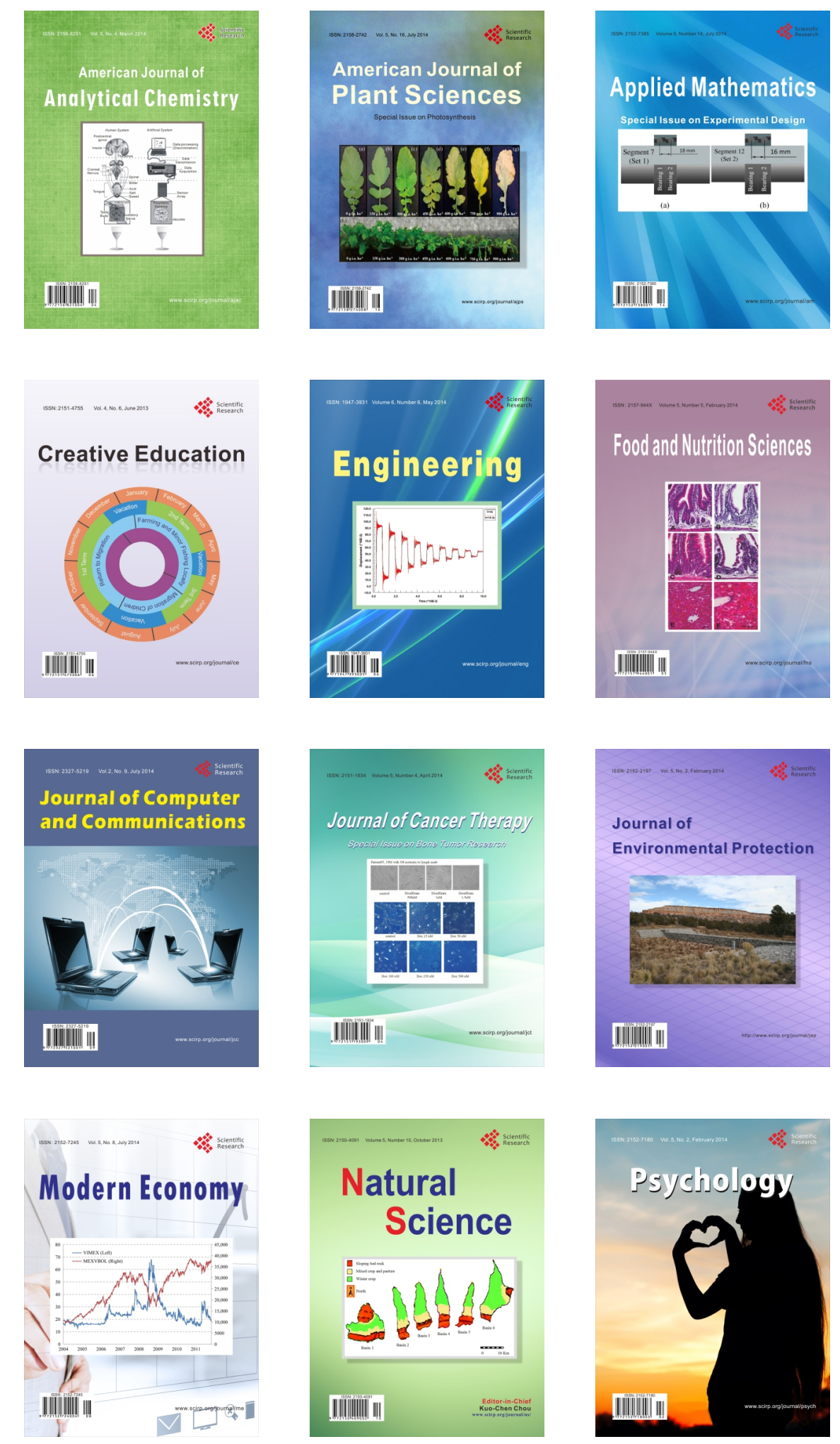